\title{
The Journal of Laryngology and Otology
}


PRINTED IN

GREAT BRITAIN BY

HEADLEY BROTHERS LTD

IO9 KINGSWAY LONDON WC2B 6PX

AND ASHFORD KENT 


\section{The Journal of Laryngology and Otology EDITED BY SIR GEOFFREY BATEMAN}

FOUNDED IN I887 BY MORELL MACKENZIE AND NORRIS WOLFENDEN

VOLUME NINETY

Publisbed for the Proprietors by HEADLEY BROTHERS LTD Ashford, Kent I 976 


\title{
The Journal of
}

\section{Laryngology and Otology}

(Founded in i 887 by Morell Mackenzie and Norris Wolfenden)

\author{
January 1976
}

\section{Contents}

Editorial-John Groves

Royal College of Surgeons

Royal Society of Medicine

Gavin Livingstone Memorial Lecture

Officers of Conference

Opening Address-The Master, JoHN ANGELL-JamEs . . . . .

Academic programme of plenary sessions . . . . . . . . $\quad$ I3

A critique of stapedectomy-Jack Var Doren Hough . . . . . I $_{5}$

The indications for stapedectomy-VAlEntine Hammond . . . . 23

Stapedectomy complicátions--RoRY WILLIS . . . . . . 3 I

'Everywhere the old order changes and happy are those who can change with it'-Howard P. House. . . . . . . . . 4I

The treatment of locally advanced cancer of the head and neck, with special reference to upper jaw tumours-Percy Helman and Rossal Sealy . $\quad 49$

Carcinoma of the Paranasal sinuses and cranial-facial resection-George A. Sisson, David E. Bytell, Stephen P. Becker and Daniel Ruge . 59

Problems in surgical management of neoplasms arising in the paranasal sinuses-D. F. N. HarRison . . . . . . . . . 69

Surgical treatment of vertigo-U. FISCH $\quad . \quad$. $\quad . \quad$. . . $\quad$. 75

The surgery of vertigo: Saccus drainage for idiopathic endolymphatic hydrops - ANDrew W. Morrison

Precancerous lesions of the mouth-IVOR R. H. KRAMER

Oral vesiculo-bullous lesions-R. HASKELL . . . . . . IOI

Treatment of superficial lesions of the mouth and pharynx-W. S. Lunv . 105

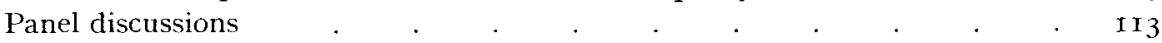

Instructional sessions . $\quad . \quad$. $\quad . \quad$. $\quad . \quad$. $\quad . \quad$. . 11.5

Films $. \quad . \quad . \quad . \quad . \quad . \quad . \quad . \quad . \quad . \quad . \quad .17$

Scientific exhibition . . . . . . . . . . . . . . . II9

General notes . . . . . . . . . . . . $12 \mathrm{I}$ 


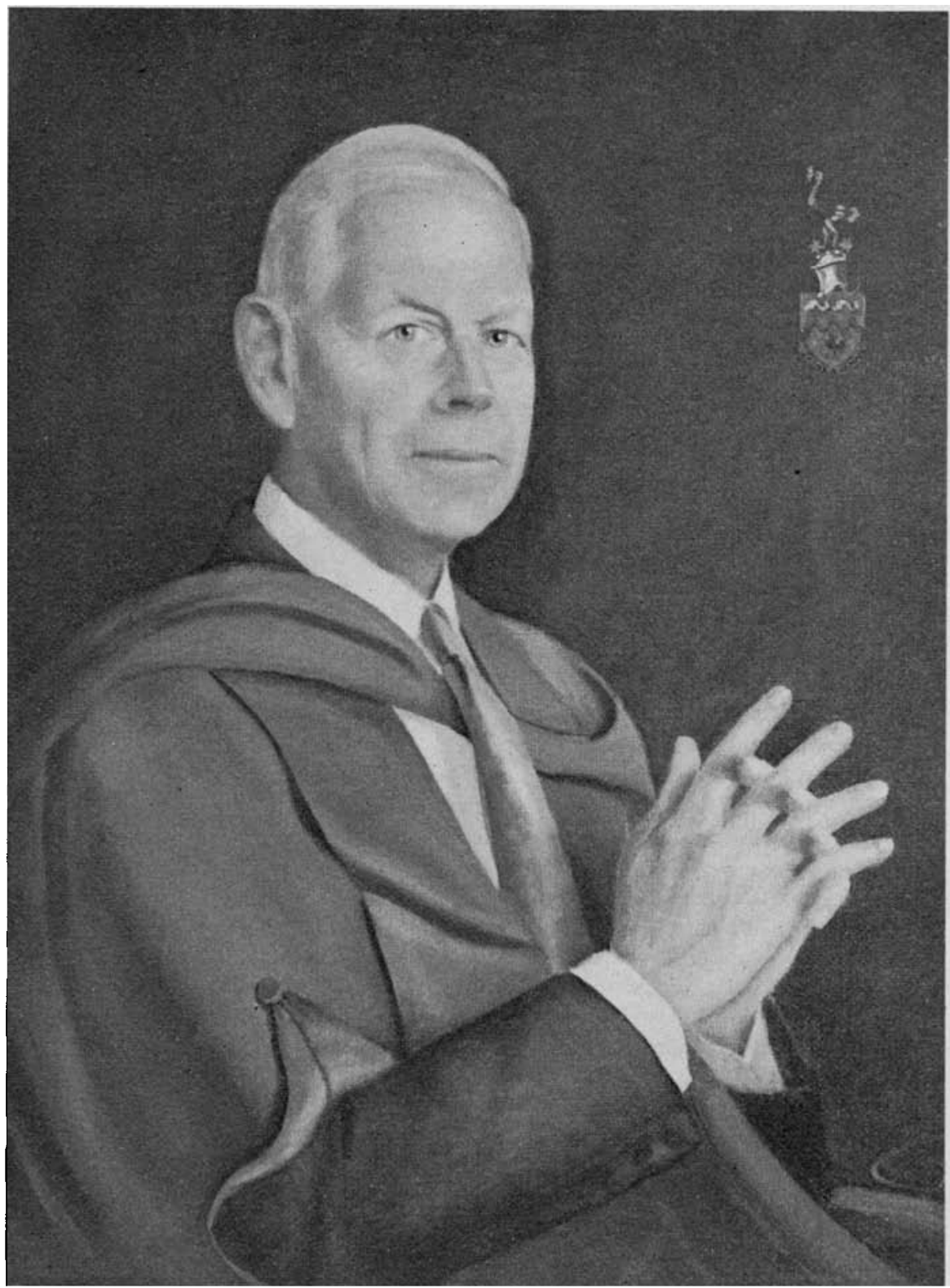

THE MASTER

MR J. ANGELL-JAMES, C.B.E., M.D., F.R.C.P., F.R.C.S. 